\title{
Três formas de segregação urbana e racial em Ponciá Vicêncio, de Conceição Evaristo
}

\author{
Three forms of urban and racial segregation \\ in Ponciá Vicêncio, by Conceição Evaristo \\ Tres formas de segregación urbana y racial \\ en Ponciá Vicêncio, de Conceição Evaristo
}

Daniela Schrickte Stoll

\section{Resumo}

O artigo analisa três formas de segregação urbana presentes no romance Ponciá Vicêncio (2003), de Conceição Evaristo: nas favelas, nos presídios e nas zonas de prostituição. Argumenta-se que essa segregação não tem apenas caráter social, mas também étnico-racial e moral. Através das trajetórias de três personagens que se mudaram do campo para a cidade grande - Ponciá e Bilisa em busca de melhores condições de vida e Luandi à procura da irmã -, evidenciam-se essas separações no espaço urbano, em diálogo com o pensamento de Célia Maria Azevedo (1987), Luiza Bairros (1995; 2000), Sueli Carneiro (2001), Vera Malaguti Batista (2004), Marilena Chauí (2008), entre outros/as. Assim, percebese a segregação social e urbana de grupos como as prostitutas, a exemplo de Bilisa, que ficam restritas ao espaço da zona, dos negros encarcerados na delegacia onde trabalha Luandi, e das domésticas que, como Ponciá, descem o morro ou atravessam a cidade até a casa das patroas. Conclui-se que Conceição Evaristo denuncia, em Ponciá Vicêncio, a hierarquização dos espaços das cidades e a continuidade da lógica racista do período colonial após a abolição da escravatura, ao mesmo tempo que constrói personagens fortes e complexas que tensionam essas fronteiras.

Palavras-chave: segregação urbana, segregação étnico-racial, literatura brasileira contemporânea, Conceição Evaristo.

\begin{abstract}
The article analyzes three forms of urban segregation in the novel Ponciá Vicêncio (2003), by Conceição Evaristo: in favelas, prisons and prostitution zones. It is argued that this segregation is not only social but also ethnoracial and moral. In the stories of three characters who move from the countryside to the big city Ponciá and Bilisa in search of better conditions of life, and Luandi in search of his sister - the segregations become evident and dialogue with the ideas of Célia Maria Azevedo (1987), Luiza Bairros (1995, 2000), Sueli Carneiro (2001), Vera Malaguti Batista (2004), Marilena Chauí (2008), among others. Thus, we can see the social and urban segregation of groups such as prostitutes, like Bilisa, restricted to the prostitution zones, or the black men imprisoned in the police station where Luandi works, as well as the maids that, like Ponciá, descend the slum or walk across the city to get to the house of their employers. In conclusion, Conceição Evaristo denounces, in Ponciá Vicêncio, a spacial hierarchy in the cities
\end{abstract}

\section{Resumen}

El artículo analiza tres formas de segregación urbana presentes en la novela Ponciá Vicêncio (2003), de Conceição Evaristo: en las favelas, en los presidios y en las zonas de prostitución. Se argumenta que esta segregación no sólo tiene carácter social, sino también étnico-racial y moral. A través de las trayectorias de tres personajes que se trasladaron del campo a la ciudad grande - Ponciá y Bilisa en busca de mejores condiciones de vida y Luandi en busca de su hermana - se evidencian esas separaciones, en diálogo con el pensamiento de Célia Maria Azevedo (1987), Luiza Bairros (1995, 2000), Sueli Carneiro (2001), Vera Malaguti Batista (2004), Marilena Chauí (2008), entre otros/as. Así, se percibe la segregación social y urbana de grupos como las prostitutas, a ejemplo de Bilisa, que quedan restringidas al espacio de la zona de prostituición, o de la población negra encarcelada en la delegación de policía donde trabaja Luandi, y de las empleadas domésticas que, como Ponciá, descienden el morro o

\footnotetext{
* Doutoranda em Literatura na Universidade Federal de Santa Catarina (UFSC), Florianópolis, SC, Brasil. (Dorcid.org/0000-00018843-779X. E-mail: sstolldaniela@gmail.com
} 
and a continuity of the racist logic of the colonial period after the slavery abolition, at the same time that she creates strong and complex characters that strain these borders.

Keywords: urban segregation, ethno-racial segregation, brasilian contemporary literature, Conceição Evaristo. atravesan la ciudad hasta la casa de sus empleadoras. Se concluye que Conceição Evaristo denuncia, en Ponciá Vicencio, la jerarquización de los espacios de las ciudades y la continuidad de la lógica racista del período colonial tras la abolición de la esclavitud, al tiempo que construye personajes fuertes $y$ complejos que tensan esas fronteras.

Palabras-clave: segregación urbana, segregación étnico-racial, literatura brasileña contemporánea, Conceição Evaristo.

Na análise do romance Ponciá Vicêncio (2003), de Conceição Evaristo, este artigo abordará a questão da segregação urbana, que é uma temática comum nas obras da autora - aparece também no romance Becos da Memória (2006) e nos contos de Olhos d'água (2015). Em Ponciá Vicêncio (2003), Conceição Evaristo evidencia tanto a segregação que ocorre nas periferias e nos morros das cidades, quanto nos presídios e nas zonas de prostituição, de modo que fique claro o caráter social, étnico-racial e moral dessa separação.

Ponciá Vicêncio, a personagem principal do romance, muda-se do campo para a cidade grande em busca de melhores condições de vida. Ela morava, até então, com a família: a mãe, artesã como ela, e o irmão, que trabalhava nas terras do coronel Vicêncio, como também fizeram o pai e o avô de Ponciá, antes de morrerem. O avô dela fora escravizado naquelas terras, e a família, mesmo depois da liberdade, ainda carregava, no sobrenome e na vida difícil, a marca da exploração dos/as brancos/as. Mesmo nas terras dos/as negros/as, a colheita também era entregue aos coronéis. Enfrentavam um luta diária e sem perspectiva. Assim, ela decidiu partir de trem para a cidade, acreditando que poderia traçar outros caminhos:

Quando o trem foi diminuindo a marcha e parou na plataforma, Ponciá Vicêncio apertou contra o peito a pequena trouxa que carregara no colo durante a viagem inteira. Levantou-se aflita e olhou desesperada lá fora à procura de alguém. Não divisou um rosto conhecido, experimentou um profundo pesar, embora soubesse de antemão que não havia ninguém esperando por ela. Não conhecia ninguém, nunca viera até a cidade e todos os seus parentes haviam ficado para trás. Nenhum deles havia ousado tamanha aventura. Estava escurecendo, Ponciá não sabia bem o que fazer. Caminhou rápido e alcançou o lado de fora da estação. Quis olhar para trás, mas temeu o desejo de recuo. Olhou em frente, uma imponente catedral, com suas luzes acesas, esperava pelos crentes, no final da avenida. O relógio da matriz era enorme, de longe conseguiu ler as horas. Eram seis. Ponciá tinha então 19 anos, sendo capaz ainda de inventar sentimentos de segurança. Caminhou firme, sempre em frente, e só parou quando chegou à escadaria do templo (Evaristo, 2003, p. 35).

Nesse trecho fica evidente a coragem de Ponciá, que chegava sozinha, sem ter para onde ir, mas andava firme e sempre em frente. Tão nova, ela era a primeira da sua família a tentar a sorte na cidade. Mas a procura de Ponciá, por oportunidades, por libertação, por espaço, era comum entre outros/as personagens da cidade grande. Ela reflete uma voz coletiva, oprimida e silenciada: a das mulheres migrantes, da população negra, das minorias.

O Brasil passou por progressivos movimentos migratórios desde o final do século XIX e início do século XX (época na qual se estima que a narrativa de Ponciá esteja situada, embora o recorte temporal não tenha sido precisamente determinado no romance, tampouco a cidade para qual ela se muda). Nesse período, houve uma série de deslocamentos das populações pobres para as capitais, e a intensificação da urbanização traçou novos desenhos para as cidades brasileiras. Ao longo do século XX, as migrações rural-urbanas aumentaram: desde 1970, quando a população rural passou a ser minoritária, até o início dos anos 2000, mais de 40 milhões de brasileiros/as migraram do campo para a zona urbana (Gonçalves, 2001). Assim, embora o local e o momento 
em que se passam a narrativa de Ponciá não tenham sido precisamente determinados, ela se recordou de outros casos antes dela:

Outros e outros casos de conhecidos que saíam do povoado a caminho da cidade e eram roubados na estação de chegada. Perdiam o pouco que tinham e ali mesmo viravam mendigos. Outros não conseguiam trabalho ou ganhavam pouquíssimo e não tinham como viver. A vida se tornava pior do que na roça. Ela sabia de muitos casos tristes, em que tudo havia dado errado. Procurou se lembrar de algum que tivesse tido um final feliz. Não lembrou. Esforçou mais e não atinou com nenhum. Não esmoreceu. Relembram tanto, falavam tanto daqueles casos tristes, que até ela só se lembrava deles. Não tinha importância. O caso dela, quando voltasse para buscar os seus, haveria de ser uma história de final feliz (Evaristo, 2003, p. 37).

Era devido a essas histórias que, no povoado, as pessoas tinham medo da cidade. Contavam o caso de Maria Pia, que trabalhava como doméstica e foi contaminada com uma doença sexualmente transmissível pelo filho do patrão; contavam o caso de Raimundo Pequeno, que aceitou vender mercadorias de procedência duvidosa e acabou preso. Havia um imaginário construído sobre a cidade - essa cidade que ficava a distância de uma longa viagem de um trem que passava no povoado apenas a cada 15 dias -, e foi esse imaginário que Ponciá enfrentou quando tomou a decisão de partir.

Ela passou a primeira noite na porta da igreja, abraçada à trouxa com seus poucos pertences, na companhia de mendigos/as, crianças, mulheres e homens. Alguns agasalharam-se em jornais para se proteger do frio. No dia seguinte, ela se encheu de coragem, pediu emprego às fiéis que frequentavam a igreja e começou a trabalhar como doméstica. Com o tempo, Ponciá Vicêncio juntou dinheiro, comprou um barraco no morro e se casou com um homem que trabalhava na construção civil.

O plano dela era voltar para buscar a família, mãe e irmão, mas, quando conseguiu voltar, não encontrou ninguém na antiga casa do povoado. Sem a companhia dos seus, "a cidade lhe parecia agora sem graça e a vida seguia sem qualquer motivo" (Evaristo, 2003, p. 74). Ponciá continuava trabalhando como doméstica e sentia falta de trabalhar como artesã, modelando o barro. Um vazio começou a tomar conta da sua cabeça. Seu marido era abusivo e violento. Ela perdeu sete filhos, que morriam logo após o parto, mas se questionava se teria valido a pena a vida dos filhos, que apenas repetiriam a vida que ela tinha.

Valeria a pena pôr filho no mundo? Lembrava-se da sua infância pobre, muito pobre na roça e temia a repetição de uma mesma vida para os seus filhos. O pai trabalhava tanto. A mãe pelejava com as vasilhas de barro e tinham apenas uma casa de pau-a-pique coberta de capim, para abrigar a pobreza em que viviam. E esta era a condição de muitos. Molambos cobriam o corpo das crianças que até bem grandinhas andavam nuas. Entretanto, assim que as meninas cresciam um pouco, as mães providenciavam panos para tapar-lhes o sexo e os seios. Crescera na pobreza. Os pais, os avós, os bisavôs sempre trabalhando nas terras dos senhores. A cana, o café, toda a lavoura, o gado, as terras, tudo tinha dono, os brancos. Os negros eram donos da miséria, da fome, do sofrimento, da revolta suicida. Alguns saíam da roça, fugiam para a cidade, com a vida a se fartar de miséria, e com o coração a sobrar esperança. Ela mesma havia chegado à cidade com o coração crente em sucessos e eis no que deu. Um barraco no morro. Um ir e vir para a casa das patroas. Umas sobras de roupas e de alimento para compensar um salário que não bastava (Evaristo, 2003, p. 82).

Esse trecho dialoga com a história de outras personagens criadas por Conceição Evaristo, como Ditinha, em Becos da memória (2006/2013), que trabalha como doméstica na casa de Dona Laura e compara a rua larga da casa da patroa com os becos da favela:

Havia andado tanto, havia tempos que não cruzava todos os becos da favela. Lembrou-se da rua da casa de Dona Laura. Larga e cheia de árvores. [...] Ditinha estava muito cansada, tinha o corpo moído. Entrara e saíra em vários becos da favela: Beco do Rala-Bunda, Beco da Cumadre Joaquina, Beco dos Dois Irmãos, Beco das Duas Marias, Beco do Sem Alma, Beco dos Namorados, Beco do Tio Totó, Beco da Dona Tacilda, Beco das Irmãs Cuícas, Beco da Cruz- 
Credo... Becos, becos, becos. Algumas pessoas, ao encontrarem com Ditinha, perguntavam se ela estava procurando os filhos. Ela procurava uma saída (Evaristo, 2013, p. 170).

Nesse ir e vir para a casa das patroas, encontrava-se também Maria, de Olhos d'água (2015), com as sobras de alimento na sacola pesada enquanto esperava no ponto de ônibus:

Maria estava parada há mais de meia hora no ponto de ônibus. Estava cansada de esperar. Se a distância fosse menor, teria ido a pé. Era preciso mesmo ir se acostumando com a caminhada. $\mathrm{O}$ preço da passagem estava aumentando tanto! Além do cansaço, a sacola estava pesada. No dia anterior, no domingo, havia tido festa na casa da patroa. Ela levava para casa os restos. O osso de pernil e as frutas que tinham enfeitado a mesa (Evaristo, 2015, p. 39).

A profissão de empregada doméstica evidencia a primeira das três formas de segregação urbana e racial que aparecem em Ponciá Vicêncio (2003) e que serão abordadas neste artigo. No Brasil, a configuração do trabalho das empregadas domésticas acaba replicando a história da escravidão, com abusos de autoridade, salários baixos, não regulamentação e assédio sexual por parte dos patrões. Há preconceitos que se refletem até mesmo na arquitetura das edificações, como a separação em elevadores "social" e "de serviço", assim como a configuração do cômodo "dependência de empregada", normalmente sem iluminação e ventilação natural, remetendo à senzala. As demarcações sociais, por vezes, incluem também o uso de uniformes e os "hábitos" da família - é comum que as domésticas não utilizem as mesmas louças e talheres que os patrões e que não façam as refeições no mesmo espaço, como ilustrou o filme Que horas ela volta?,1 de Ana Muylaert (2015).

Segundo Luiza Bairros (1995), que foi uma intelectual, militante brasileira e ministra da igualdade racial no governo Dilma Roussef (2011-2016), o que se espera das domésticas é que cuidem do bem-estar dos/as outros/as e com eles/as desenvolvam até laços afetivos, enquanto devem se submeter à exploração econômica e permanecer estranhas ao ambiente do qual participam. No entanto, esse trabalho "permitiu a mulher negra ver a elite branca a partir de uma perspectiva a que os homens negros e nem mesmo os próprios brancos tiveram acesso" (Bairros, 1995, p. 463), ou seja, elas puderam ver as contradições entre as ideologias e as ações do grupo dominante (Bairros, 1995). Em outro artigo, Bairros recuperou o pensamento de Lélia Gonzalez (1983), que argumentou que as domésticas carregam a sua família e a dos outros nas costas. Além disso, ainda que oficialmente a conotação sexual da palavra africana "mucama" tenha se perdido, na prática, a empregada doméstica negra é alvo de sexualização por parte dos/as brancos/as, acostumados a ouvir e reproduzir o estereótipo da mulata fogosa (Bairros, 2000, s.p.).

No Brasil, o fato de muitas mulheres, provenientes da periferia, atravessarem as cidades para cuidar dos lares de outras mulheres, foi o que permitiu que estas pudessem ganhar maior mobilidade e se lançar em suas carreiras, enquanto aquelas continuam presas por um sistema que pouco ou nada as enxerga. Aqui se pode observar o ponto da geógrafa inglesa Doreen Massey (1994/2009), que explica como as mobilidades dos sujeitos são diferentes e, mais do que isso, como a mobilidade de alguns/umas, de fato, acaba por aprisionar outros/as. Essa abordagem vai contra a história linear das mulheres que conquistaram o direito de circular pelo espaço público, que diz respeito unicamente às mulheres brancas de classe média, que se lançaram no mercado de trabalho, enquanto muitas mulheres negras, pobres e periféricas, pelo contrário, continuaram cuidando de lares que não eram os seus, sub-remuneradas e enfrentando diversas opressões de gênero e de raça.

Ponciá, portanto, mesmo longe das terras onde a família fora escravizada, percebeu que a herança colonial a alcançava também na cidade, porque, conforme explica a filósofa brasileira Sueli Carneiro (2001/2011), as reminiscências do período colonial permanecem vivas no imaginário social e adquirem novas funções nesta ordem social supostamente democrática que mantêm intactos o racismo e as relações de gênero instituídas no período da escravidão. Os espaços da cidade eram outros, mas mantinham a mesma lógica de hierarquização que ela

${ }^{1} \mathrm{O}$ filme recebeu críticas por não ter optado por uma atriz negra para o papel da personagem principal, como percebe-se no texto de Débora Carvalho (2015). 
encontrara no campo, agora sob o disfarce da democracia racial. No Brasil, o mito da democracia racial torna as distâncias sociais ainda mais mascaradas e naturalizadas - e esse mito, que originou as construções de nossa identidade nacional, "está ancorado na violação colonial perpetrada pelos senhores brancos contra as mulheres negras e indígenas e na miscigenação daí resultante" (Carneiro, 2011, s.p.).

O caráter espacial-geográfico da separação, nas cidades brasileiras, entre os bairros ricos e os bairros pobres, ou centro e periferia, evidencia as separações de ordem social. Isso fica evidente no caso das favelas, segundo a filósofa brasileira Marilena Chauí (2008), pois, nesse caso, a separação nem sempre é geográfica, e as favelas ocupam "bolsões" no próprio "centro", mas a separação social permanece: a cidade olha para a favela como uma "realidade patológica, uma doença, uma praga, um quisto, uma calamidade pública" (Chauí, 2008, p. 73). Isto é, a mesma lógica colonial da casa grande/senzala, traduzida no tecido urbano como centralidades/periferias (Moassab, Berth e Hoshino, 2016). Nesse contexto, segundo Andréia Moassab, Joice Berth e Thiago Hoshino (2016, s.p.), "as cidades exprimem os conflitos e desigualdades da produção do espaço, ao mesmo tempo em que os acirram e (re)produzem". Para os/as autores/as, o urbanismo é flagrantemente eurocentrado, ignora o impacto do racismo nas principais decisões geopolíticas num quadro de desenvolvimento geográfico desigual e colabora para aprofundar não apenas a segregação socioespacial, mas também a segregação étnico-racial (Moassab, Berth e Hoshino, 2016).

O vazio que toma conta de Ponciá pode ser também uma consequência da tomada de consciência dessas realidades, como ela demonstra nessa passagem:

De que valera o padecimento de todos aqueles que ficaram para trás? De que adiantara a coragem de muitos em escolher a fuga, de viverem o ideal quilombola? [...] A vida escrava continuava até hoje. Sim, ela era escrava também. Escrava de uma condição de vida que se repetia. Escrava do desespero, da falta de esperança, da impossibilidade de travar novas batalhas, de organizar novos quilombos, de inventar outra e nova vida (Evaristo, 2003, p. 83).

Então, em vez de se ajustar à lógica da cidade, Ponciá não se deixa moldar. Ela resiste, primeiro através da "loucura" que nela se manifesta, esse vazio no qual ela vai se adentrando e, depois, com seu retorno final ao campo. Mas antes do retorno dela, a narrativa traz a história do irmão de Ponciá, Luandi, que partiu para a cidade em busca da irmã e de melhores condições de vida. Como se verá a seguir, esse personagem introduz o segundo exemplo de segregação urbana e racial no romance: os presídios.

Luandi "chegou num dia de chuva e frio. Trazia muita fome também" (Evaristo, 2003, p. 69). Suas primeiras reflexões, já na cidade, aparecem assim:

Estava calçado pela primeira vez. Na roça sempre andara de pés no chão. As luzes dos postes querendo tapear a escuridão da noite aborrecia profundamente o moço. "Para que eu vim para a cidade?", perguntou-se entre os dentes, resmungando, como era hábito de seu pai. "Para que eu vim para a cidade?", se perguntou novamente. Achar minha irmã, juntar dinheiro e ficar rico. É, ele havia de ficar rico. Diziam que na cidade as pessoas trabalham muito, mas ficam ricas. E de trabalho Luandi não tinha medo. [...] Como localizar a irmã? Na roça é só andar pelo povoado e, quando não se encontra a pessoa do nosso desejo, um ou outro apazigua a aflição da gente. Traz notícias ou leva um recado para a pessoa procurada. Mas ele sabia o que deveria fazer. No outro dia haveria de andar a cidade inteira. Tantos haviam saído da roça e estavam ali! Na certa, se não encontrasse logo Ponciá, encontraria alguém que saberia dizer do paradeiro dela (EVARISTO, 2003, p. 69).

Ele decidiu passar aquela primeira noite na estação, no entanto foi acordado por um soldado que pediu seus documentos e o revistou. Assim, Luandi passou a noite na cela da delegacia. Essa abordagem é comum para as pessoas negras, tratadas como criminosas nas ruas. Na contemporaneidade, ocorre um encarceramento em massa da população negra, que, assim como a segregação urbana, tornou-se outra forma de afastar a parte da população que é tida como pobre, indesejável e perigosa. Segundo Loïc Wacquant (2008), sociólogo estadunidense que analisa o sistema prisional dos Estados Unidos - onde, entre 1975 e 2000, a população carcerária passou de 380 mil para 2 milhões de detentos/as -, a prisão é uma forma de administração da pobreza. Para 
o autor, a prisão carrega agora novas funções, como gerir o trabalho não regulamentado, a hierarquia étnico-racial e a marginalidade urbana nos Estados Unidos. Conforme Alessandro De Giorgi (2004), doutor em criminologia na Inglaterra, a partir dos anos 1970, houve, nos países ocidentais, uma transição de um modelo de democracia "social" para uma democracia "punitiva", que define novas formas de exclusão e novos limites de seleção no acesso à cidadania. Segundo o autor, o objeto dessa repressão é a nova marginalidade social:

As minorias étnicas na América, os imigrantes na Europa, os novos pobres, os desocupados e os tóxico-dependentes em ambos os contextos. Trata-se de um processo de "criminalização em massa", voltado contra categorias inteiras de sujeitos selecionados segundo caraceterísticas de gênero, étnicas, raciais e econômicas (De Giorgi, 2004, p. 29-30).

Mas o contexto de Luandi era o Brasil das primeiras décadas do século XX, melhor entendido pela abordagem da socióloga brasileira Vera Malaguti Batista (2004), que analisa a difusão do medo, do caos e da desordem como forma de detonar estratégias de disciplinamento e controle das massas empobrecidas, através de uma avaliação do Rio de Janeiro do século XIX. Segundo a autora, o período posterior à Independência do Brasil (1822) revelou diferentes desejos de nação. Ao mesmo tempo que o "povo brasileiro" irrompeu como uma nova categoria - uma nação mestiça, que ensejava uma radicalização do liberalismo e ansiava pelo fim da escravidão, com cidadania para todos/as -, é também nesse momento que a resistência negra se intensificou e, consequentemente, houve um aumento da inquietação dos/as proprietários/as de escravos, ansiosos/as por manter a sociedade estruturada em hierarquias. Nessa conjuntura, surgiram as primeiras faculdades de direito e ocorreu a "convergência das forças policiais, militares e paramilitares na construção de um sistema social formal organizado sempre contra a ralé" (Batista, 2004, p. 121). Naquele momento, de acordo com a autora, no Rio de Janeiro, 80\% dos/as acusados/as estavam entre os/as escravizados/as.

O decreto de novembro de 1825, que criou os cargos de comissário, lhe atribuíam: impedir ajuntamentos, reprimir a vadiagem, cadastrar os capitães-do-mato, erradicar os quilombos e açoitar em locais públicos. É assim que se funda a arquitetura legal e institucional da polícia no Rio de Janeiro e no Brasil (Batista, 2004, p. 121).

Batista afirma que o "açoite" logo saiu das ruas e foi para a prisão, e o controle social não se deu apenas no poder jurídico-social. Houve também um poder médico, ou seja, uma ação higienista nas cidades, fundamentada numa medicina que, no Brasil do século XIX, se institucionalizava no sentido das ciências iluministas, e produzia tanto uma patologização dos/as afro-brasileiros/as quanto uma depreciação da medicina africana. Assim, os/as afrobrasileiros/as foram transformados/as em obstáculo à higiene e à saúde pública.

Para fundamentar sua argumentação, a autora analisou os discursos do medo nos jornais e pasquins da época. Segundo ela, as ruas estavam "quentes" com motins, saques, rebeliões, capoeira e batuques. As notícias

vão fazendo a crônica da microfísica do poder e dos interstícios do medo branco: tiroteios nos morros, negros armados, magotes de africanos pelas esquinas etc... Aparecem várias ideias-força presentes até hoje nos discursos do medo: o descaso com a morte dos africanos e a indignação com a morte dos brancos, as estratégias seletivas de policiamento, o apelo às tropas nos quartéis, as queixas contra a impunidade, apelos por mais rigor e mais dureza no combate aos perigos da cidade (Batista, 2004, p. 123).

Aparece também o medo da organização coletiva que os/as senhores/as, inicialmente, não suspeitavam existir entre os/as africanos/as, como ocorrido na Revolta dos Malês. ${ }^{2}$ Segundo Batista (2004), a repercussão da insurreição Malê concretizou um espetáculo de medidas enérgicas contra os/as negros/as, como o açoitamento coletivo de 700 deles/as nas estradas da província fluminense.

Para a autora, "a naturalização desses discursos têm consequências estéticas, concretizam-se espacialmente, criam cenários, entram pelos olhos no cotidiano da cidade" (Batista, 2004, p. 123). Ela cita

${ }^{2}$ Essa revolta foi retratada no romance Um defeito de cor (2008), de Ana Maria Gonçalves. A narrativa é inspirada na trajetória de Luiza Mahin, que esteve envolvida na organização da Revolta dos Malês, em Salvador. 
a professora brasileira Gizlene Neder (1997), que analisa o controle do espaço na cidade e afirma que, nos momentos históricos de crise ou embate entre diferentes "projetos de cidade", emergem visões hiperbólicas sobre as classes perigosas. Na luta pelo controle social, a ação da polícia ajuda a estabelecer uma cartografia da hierarquização. As cidades se tornam, assim, cidades de fronteiras.

A análise da pesquisadora brasileira Célia Maria Azevedo (1987) sobre a época da transição da escravização para o trabalho livre, no Brasil, segue pelo mesmo caminho. Para Azevedo, a partir de 1887, começaram a ocorrer fugas massivas de pessoas escravizadas, assim como manifestações de negros/as nas ruas das cidades. No entanto, o imaginário que se tem até hoje a respeito da abolição da escravatura é de que elites liberais, humanitárias, progressistas e pacifistas conquistaram essa vitória ao se posicionarem a favor do trabalho livre, ou seja, uma luta da qual os/as brancos/as são protagonistas. Essa imagem encontrou reforço nas políticas tanto de imigrantistas quanto de alguns/umas abolicionistas, culminando na ideia de que o Brasil é um país racialmente democrático. A partir de então, o imaginário do medo, centrado na figura do/a negro/a rebelde e instável que exigia permanente controle por parte dos/as brancos/as, foi cedendo lugar ao imaginário da paz e do progresso centrado na figura do/a imigrante europeu/eia, trazido/a para o Brasil com o intuito de atender a uma demanda de mão de obra demanda que, segundo o argumento dos/as imigrantistas, existia devido ao fato de que os/as negros/as seriam incapacitados/as para o trabalho livre, pois pertenciam a uma raça inferior que tendia à ociosidade e ao crime. A adesão ao racismo científico, então, foi proporcional à exacerbação das lutas entre escravos/as e senhores/as. Segundo a pesquisadora, houve também uma pressão para que os/as negros/as se direcionassem para o campo, deixando as áreas urbanas livres para o trabalho dos/as imigrantes, já que as cidades eram consideradas como "o espaço privilegiado do progresso" (Azevedo, 1987, p. 166).

O irmão de Ponciá, mais tarde, começou a trabalhar como faxineiro da própria delegacia onde esteve preso e passou a sonhar com o desejo de se tornar soldado. Luandi observava os presos que chegavam: no seu primeiro dia de trabalho, chegou um "rapaz meio amulatado de olhos claros que tinha sido pilhado rondando o armazém dos espanhóis, que ficava perto da delegacia" (Evaristo, 2003, p. 72). Então ele refletiu:

$\mathrm{O}$ momento de que ele mais gostava era quando chegavam os presos. Alguns chegavam assustados, acuados. Outros vinham com as feições carregadas de ódio. Ele ficava encarando um por um na tentativa de descobrir quem era culpado e quem era inocente. Tinha a impressão, às vezes, de que todos eram inocentes, mas ao mesmo tempo culpados. Seu coração doía um pouco. Sentia-se também preso em cada um deles (Evaristo, 2003, p. 73).

$\mathrm{O}$ fato de ele se sentir preso em cada um deles sugere que os rapazes eram negros como ele e como o "rapaz amulatado", por isso a identificação. Luandi sente que podia estar ali, no lugar deles, como esteve na primeira noite em que chegou à cidade. Assim como o "rapaz amulatado" fora preso sem motivo, apenas por estar "rondando o armazém", Luandi fora preso por estar dormindo na estação, o que evidencia o fator racial por trás das prisões.

A figura do soldado, segundo o psiquiatra e filósofo martiniquense Frantz Fanon (1961/1968, p. 28), representa o porta-voz do colonizador e do regime de opressão. A linha divisória (fronteira) do mundo colonizado, dividido em dois, é indicada pelos quartéis e delegacias de polícia. A presença da delegacia, no romance de Conceição Evaristo, explicita essa linha divisória, e o personagem de Luandi demonstra o desejo de ser assimilado, de poder passar para o outro lado desse mundo dividido em dois, tornando-se respeitado no papel de opressor, um desejo que vem acompanhado de sentimentos contraditórios.

Na construção da identidade do homem negro, desde o início da colonização, a contradição esteve presente, segundo pondera o professor brasileiro Mario Lugarinho (2017). Para o autor, as identidades masculinas sofreram interferências radicais por ocasião da expansão colonial europeia. Na África subsaariana, por exemplo, "a autonomia feminina e os largos arranjos familiares foram esvaziados pela imposição colonial da figura do chefe de família (personagem social quase desconhecido no continente), seguido da redução do grupo à família nuclear" (Lugarinho, 2017, p. 143). O homem negro africano passou a experimentar uma condição dupla e contraditória: por um lado passou a exercer um protagonismo que antes não possuía (como 
chefe de família), por outro, foi reduzido a posições subalternas "cúmplices ou marginais àqueles que efetivamente exerciam o poder na colônia (os homens brancos europeus)" (Lugarinho, 2017, p. 143). No romance, o irmão de Ponciá Vicêncio procura construir sua identidade sempre em relação à de Soldado Nestor, soldado negro que o prendeu na estação, na primeira noite. Mas o que Luandi admirava era a posição de soldado, a voz de comando, que ele associava aos brancos: "Luandi só queria ser soldado. Queria mandar. Prender. Bater. Queria ter a voz alta e forte como a dos brancos" (Evaristo, 2003, p. 71). Ou seja, a contradição de uma identidade ao mesmo tempo cúmplice do poder do homem branco e marginal a ele.

Luandi, então, se apaixona por Bilisa, mais uma personagem que havia migrado do campo para a cidade. A história de Bilisa introduz a terceira forma de segregação apresentada pelo romance e começa assim:

Viera com a ideia de trabalhar. Trabalhou muito, juntou algum dinheiro com o propósito de voltar à casa dos pais para buscá-los e os irmãos. Um dia, não se sabe como, a caixinha de dinheiro que ela guardava no fundo do armário sumiu. Sumiram as economias, o sacrifício de anos e anos. Bilisa se desesperou. Ninguém entrava em seu quarto a não ser, de vez em quando, o filho da patroa. Sim, ele era o único que entrava lá, às vezes, quando dormia com ela. Só podia ter sido ele a tirar o dinheiro por brincadeira, para assustá-la talvez. A patroa não gostou da suspeita que caiu sobre o seu filho. Quanto a dormir com a empregada, tudo bem. Ela mesma havia pedido ao marido que estimulasse a brincadeira, que incentivasse o filho à investida. $\mathrm{O}$ moço namorava firme uma colega de infância, ia casar em breve e a empregada Bilisa era tão limpa e parecia tão ardente. Bilisa não encontrou o dinheiro e nunca mais viu o filho da patroa (Evaristo, 2003, p. 98).

Bilisa reconhecia que era "ardente" e não se importava que a chamassem de puta. "Puta é gostar do prazer. Eu sou. Puta é esconder no mato com quem eu quero? Eu sou. Puta é não abrir as pernas para quem eu não quero? Eu sou" (Evaristo, 2003, p. 99). Assim, para recuperar o dinheiro mais rapidamente, em vez de voltar à cozinha, à arrumação da casa, ao tanque, ao ferro de passar roupa, ela decide trabalhar na zona. No entanto, quando conheceu Luandi, já vivia assim há cinco anos e ainda não tinha conseguido juntar dinheiro, pois precisava reparti-lo com o cafetão Negro Climério e com a dona do prostíbulo. Para Simone Schmidt (2016, p. 18), a história de Bilisa guarda uma aproximação assustadora com a vivência da escravidão, quando mulheres negras eram abusadas pelos seus senhores, homens brancos que eram os únicos sujeitos do desejo. ${ }^{3} \mathrm{O}$ filho dos patrões de Bilisa personifica esse sujeito, pois a "investida" partira dele, assim como o roubo do dinheiro dela e o posterior desaparecimento (para se casar com a colega provavelmente branca), sempre apoiado e instigado pelos pais. Uma relação hierarquizada que replica a história das relações entre colonizadores e colonizadas, marcada por questões de gênero e raça. Depois de Bilisa ter vivido como prostituta durante cinco anos, sua história termina de maneira breve e trágica, com a moça sendo assassinada por Negro Climério.

As zonas (ou espaços prostitucionais) costumam ser áreas bem delimitadas nas cidades, espaços também segregados e destinados aos grupos "desviantes", conforme explica Diana Ramos (2015). Para Ramos, a segregação urbana pode ser dividida em três vetores, que interagem na constituição dos espaços prostitucionais:

1) a segregação por diferenças econômicas e de classe social; 2) a segregação em função de comunidades étnicas e/ou raciais; e 3) a segregação por separações ligadas à moralidade e ao perigo de contágio social em função de grupos considerados "desviantes". Os espaços prostitucionais fazem parte de uma dinâmica recorrente de segregação de práticas e, por meio delas, de indivíduos e grupos considerados marginais. No entanto, vale ressaltar, que mesmo que um desses três vetores atue em destaque, todos eles trabalham de forma integrada na constituição dos espaços prostitucionais. Afinal, essa "cidade maldita" /"região moral"/gueto está alocada, de forma geral, em áreas desvalorizadas não apenas

\footnotetext{
${ }^{3}$ De acordo com Schmidt (2016), essa ideia (dos homens brancos europeus como únicos sujeitos do desejo - e da história) foi elaborada por Denise Ferreira Silva (2006).
} 
simbolicamente mas também materialmente: com infraestrutura urbana abandonada, obsoleta, precária ou inexistente (Ramos, 2015, p. 176-177).

Segundo a autora, quando entrou em vigor a Lei da Vadiagem (1880), que autorizava prender aqueles/as "sem trabalho", a penalidade recairia principalmente sobre as pessoas negras (que após a Abolição da Escravatura disputariam trabalho com imigrantes europeus/eias incentivados/as a vir para o Brasil), mas recairia também sobre as prostitutas. ${ }^{4} \mathrm{Na}$ classificação e organização dos usos urbanos da cidade, pessoas negras desempregadas e prostitutas precisavam ficar afastadas dos locais de "família". O local destinado a essas pessoas "impuras" não podia ser o mesmo por onde transitavam as "senhoras". Assim como os/as doentes, vadios, ${ }^{5}$ loucos/as, rebeldes, velhos/as ou menores órfãos/ãs e abandonados/as, essas eram categorias que precisavam ser ocultas, invisibilizadas.

Por isso, para Ramos, a prostituição é mais tolerada e tem maior duração em bairros em "transformação", com terrenos vagos, atividades obsoletas ou pouco definidas e com valor imobiliário médio, habitados por uma população desprovida de recursos materiais. Ela cita Gabriela Leite (1992), que foi uma das principais representantes do movimento organizado de prostitutas no Brasil e afirmou que, nas zonas em geral: "as casas estão caindo aos pedaços, e essa falta de manutenção está, invariavelmente, associada à degradação do viver clandestino que é introjetado assim: as prostitutas só podem viver em coisa ruim" (Leite, 1992, p. 126 apud Ramos, 2015, p. 177).

No romance de Conceição Evaristo, portanto, percebe-se a segregação social e urbana de grupos como as prostitutas, a exemplo de Bilisa, que ficam restritas ao espaço da zona, dos negros encarcerados na delegacia onde trabalha Luandi, e das domésticas que, como Ponciá, descem o morro ou atravessam a cidade até a casa das patroas. Todas essas segregações são transpassadas pelo determinante racial.

É importante observar que Conceição Evaristo denunciou todas essas opressões e, ao mesmo tempo, criou personagens fortes, independentes, criativas e complexas. Ao final do romance, Ponciá encontra-se com o irmão e a mãe, e os três retornam ao campo. A força da narrativa esteve nesse conjunto multidimensional de personagens que trazem à tona uma voz coletiva que tensiona as fronteiras e os limites dos espaços da cidade.

O retorno de Ponciá ao campo também marca um movimento de escolha, de apropriação dos seus próprios deslocamentos, em contraposição à trajetória dos deslocamentos forçados que acompanhou a história dos/as negros/as escravizados/as. Voltar às suas terras não significa passividade e conformismo. Pelo contrário, o retorno simboliza o fortalecimento da família junto aos seus. No povoado, a arte de Maria e Ponciá Vicêncio estava em todas as casas, o que representa uma tradição das mulheres, uma valorização e um respeito pelas duas. Em casa, a família talvez pudesse esquecer o contraste que o deslocamento tornara evidente, entre brancos/as e negros/as, lembrete constante das relações de poder, conforme pontuado por Bell Hooks (1991), que narra a sensação que tinha ao voltar para casa:

Ah! Aquela sensação de segurança, de chegada, de voltar para casa quando finalmente alcançávamos as bordas do terreno, quando podíamos ver o rosto negro do nosso avô, Daddy Gus, sentado na sua cadeira na varanda, sentir o cheiro do seu cigarro e descansar no seu colo. Que contraste, a ternura desse sentimento de chegada em casa com o amargor da viagem, aquele constante lembrete do poder e do controle brancos (Hooks, 1991, p. 41, tradução nossa).

No final do romance, então, fica uma espécie de "dupla consciência" (Du Bois, 1903), em que há uma dualidade entre o entendimento e a esperança, tão característica das obras de Conceição.

\footnotetext{
${ }^{4}$ Essa informação, segundo a autora, se baseia em MACIEL, Cleber da Silva. Discriminações raciais: negros em Campinas (18881926): alguns aspectos. Dissertação (Mestrado em História) - Instituto de Filosofia e Ciências Humanas/Unicamp, Campinas, 1985.

${ }^{5}$ Não é possível usar vadios/as porque o significado de homens vadios (preguiçosos, ociosos) é diferente do significado de mulheres vadias (putas), ou seja, um sexismo inserido na linguagem.
} 


\section{Referências}

AZEVEDO, Celia M (1987). Onda negra, medo branco: o negro no imaginário das elites do século XIX. Rio de Janeiro: Paz e Terra.

BAIRROS, Luiza (1995). Nossos feminismos revisitados. Estudos Feministas, Florianópolis, v. 3, n. 2, p. 458463. Disponível em: https:/ / bit.ly/2KRuftB. Acesso em: 12 jun 2017.

BAIRROS, Luiza (2000). Lembrando Lélia Gonzalez. Afro-Asia, Salvador, n. 23, p. 1-21. Disponível em: https:// bit.ly/2NtsGln. Acesso em: 12 jun. 2017.

BATISTA, Vera (2004). O medo na cidade do Rio de Janeiro. Delito y sociedad: Revista de Ciencias Sociales, Santa Fé, v. 1, n. 20, p. 119-126. Disponível em: https:/ / bit.ly/2NuHWyz. Acesso em: 12 jun. 2017.

CARNEIRO, Sueli (2001/2011). Enegrecer o feminismo: a situação da mulher negra na América Latina a partir de uma perspectiva de gênero. Geledés, São Paulo, 6 mar. On-line. Disponível em: https:// bit.ly/2D8W8oP. Acesso em: 11 jul. 2018.

CARVALHO, Débora (2015). Te colocando no teu devido lugar: sobre as empregadas domésticas brancas do filme A que horas ela volta?. Drops - Vitruvius, São Paulo, ano 16, n. 097.06, 16 out. On-line. Disponível em: http://www.vitruvius.com.br/revistas/read/drops/ 16.097/5769. Acesso em: 13 nov. 2017.

CHAUÍ, Marilena (2008). Cultura e democracia. Crítica y emancipación, Buenos Aires, ano 1, n. 1, p. 53-76. Disponível em: https:/ / bit.ly/2U8YYIF. Acesso em: 15 jan. 2017.

DE GIORGI, Alessandro (2011). Neoliberalismo e controle penal na Europa e nos Estados Unidos: a caminho de uma democracia punitiva? Tradução de Maria Lúcia Karam. Veredas do Direito, Belo Horizonte, v. 1, n. 3, p. 29-42. Disponível em: https:/ / bit.ly/2TZIDAW. Acesso em: 11 jun. 2017.

DU BOIS, William E. B. (1903). Of our spiritual strivings. In: DU BOIS, William E. B. The souls of black folk. Disponível em: https://faculty.uml.edu/sgallagher/WEBDuBois-Souls_of_Black_Folk-1-14.pdf. Acesso em: 11 jun. 2017.

EVARISTO, Conceição (2003). Ponciá Vicêncio. Belo Horizonte: Mazza.

EVARISTO, Conceição (2006/2013). Becos da memória. Florianópolis: Mulheres.

EVARISTO, Conceição (2015). Olhos d'água. Rio de Janeiro: Pallas: Biblioteca Nacional.

FANON, Frantz (1961/1968). Os condenados da terra. Tradução de José Laurênio de Melo. Rio de Janeiro: Civilização Brasileira.

GONÇALVES, Alfredo (2001). Migrações internas: evoluções e desafios. Estudos avançados, São Paulo, v. 15, n. 43, p. 173-184. Disponível em: https://bit.ly/2Hm1Mbl. Acesso em: 17 fev. 2017.

GONZALES, Lélia (1983). Racismo e sexismo na cultura brasileira. In: SILVA, Luiz Antônio Machado et al. Movimentos sociais urbanos, minorias étnicas e outros estudos. Brasília: ANPOCS. p. 223-244.

HOOKS, Bell (1991). Yearning: race, gender, and cultural politics. London: Turnaround.

LEITE, Gabriela (1992). Eu, mulher da vida. Rio de Janeiro: Rosa dos Tempos.

LUGARINHO, Mário (2017). Paradigmas confrontados: algumas masculinidades nas literaturas africanas de língua portuguesa. Metamorfoses, Rio de Janeiro, v. 14, n. 1, p. 141-151. Disponível em: https:// revistas.ufrj.br/index.php/metamorfoses/article/view/10553/7849. Acesso em: 11 nov. 2017.

MASSEY, Doreen (2009). Space, place and gender. Minneapolis: University of Minnesota Press.

MOASSAB, Andréia; BERTH, Joice; HOSHINO, Thiago (2016). As marcas urbanas da violência colonial. Gazeta do Povo, Curitiba, 11 jul. 2016. On-line. Disponível em: https:/ / bit.ly/33TggsJ. Acesso em: 11 jun. 2017.

NEDER, Gizlene. Cidade, identidade e exclusão social. Revista Tempo, Rio de Janeiro, v. 2, n. 3, p. 106-134, 1997.

QUE HORAS ela volta? Roteiro e direção de Ana Muylaert (2015). Coordenação executiva de Sônia Hamburguer. Brasil: Gullane; Africa Filmes; Globo Filmes; Pandora Filmes distribuidora, 2015. 1 DVD (114 minutos), son., color. 
RAMOS, Diana (2015). "Preta, pobre e puta": a segregação urbana da prostituição em Campinas - Jardim Itatinga. Tese (Doutorado em Planejamento Urbano e Regional) - Universidade Federal do Rio de Janeiro, Rio de Janeiro.

SCHMIDT, Simone P. (2016). Sexo, raça e gênero na lógica colonial: o que contam as mulheres. In: ZINANI, Cecil; SANTOS, Salete (Org.). Trajetórias de literatura e gênero: territórios reinventados. Caxias do Sul: Educs.

SILVA, Denise Ferreira da (2006). À brasileira: racialidade e a escrita de um desejo destrutivo. Revista Estudos Feministas, Florianópolis, v. 14, n.1, p. 62-83.

STOLL, Daniela Schrickte (2017). Deslocamentos urbanos na literatura brasileira contemporânea de autoria feminina. Dissertação (Mestrado em Literatura) - Universidade Federal de Santa Catarina, Florianópolis.

WACQUANT, Loïc (2008). O lugar da prisão na nova administração da pobreza. Revista Novos Estudos CEBRAP, São Paulo, n. 80, p. 9-19. Disponível em: https://bit.ly/1NW6G8g. Acesso em: 11 jun. 2017. 